\title{
European Society of Cardiology Working Group on Embryology and Teratology
}

The first meeting of the working group was held 4 and 5 November 1982 at Alderley Park, Macclesfield, U.K., by kind permission of Imperial Chemical Industries PLC. It was attended by 24 members who had been invited by the Chairmen (Professors A. E. Becker and T. Pexieder) as representing the active centres for Cardiac Embryology within Europe. The programme had been arranged by the Local Organizer, Professor R. H. Anderson, so as to stimulate discussion and to lead the way towards a programme for cooperative research into the development and structure of the heart.

\section{Nomenclature of the embryonic heart}

The opening session was concerned with the nomenclature of the embryonic heart and its correlation with cardiac morphology. Professor Anderson led off with an account of the value of descriptive nomenclature in the formed heart. The problems inherent in the use of nominative terms in embryology were then highlighted by Professor Pexieder, who recounted the many and varied terms used to describe the developing heart. He showed how the use of the same term for different purposes by different investigators self-evidently led to confusion, in many instances underscoring controverses which were more apparent than real. This led to discussion about the need to separate the different phases of cardiac development, and to avoid using potentially confusing terms (e.g. bulbus). Also considerable differences between the animal species used for study were emphasized. The formulation of a nomenclature proposal was therefore held over for the final session.

\section{Derivation of the different portions of the embryonic heart}

Dr M. V. de la Cruz described her marking experiments, derived from those of Rychter, and illustrated how they had shown the five-chamber concept of the developing chick heart to be simplistic. Professor J. A. Los then showed how the very use of the term 'segment' was inappropriate as generally used in embryology. The problem of boundaries of structures was aired. It was agreed that chosen terms must be practical, and that they should not lead to a potential conflict with terms used for the formed normal heart, nor should they imply any causal relationship until this was proven. It was recognized that different terms would likely be required for the different stages of growth.

\section{Ventricular septation}

Professor Becker opened with an account of the definitive septum, showing how the tripartite approach to description simplified categorization of septal defects. Dr A. C. G. Wenink then gave an account of his recent studies of the development of the ventricular septum, introducing the concept of a primary muscular septum subsequently joined by inlet and outlet muscular structures before the whole septation process was completed by elaboration of the membranous septum. This was followed by a detailed analysis by Dr M. Arteaga of the contribution of the atrioventricular endocardial cushions to the muscular ventricular septum in the chick. Convincing evidence was provided by using Indian ink marking techniques. Discussion followed two main lines, one being the differences between bird and mammalian hearts and the other the reliability of the marking technique.

\section{Ventricular septal defects}

Dr A. Gittengerger-de-Groot showed how the concept of Dr Wenink accounted well for the many types of ventricular septal defect, particularly those which illustrated non-fusion or malalignment of the different components of the muscular septum. Discussion emphasized that development of the atrioventricular valves was a late event, occurring quite some time after the completion of ventricular septation. Dr Wenink then further developed this theme in the setting of atrioventricular septal defects ('atrioventricular canal malformations'). Professor Pexieder concluded the session by describing Rychter's experimental production of septal defects in the chick heart. He further compared their pathogenesis with that of other animal models (Keeshond dog, fetal mouse trisomy and druginduced $\mathrm{CHD}$ ).

\section{Outflow portion}

Professor Pexieder opened the discussion in the 
first session of the second day devoted to development of the left ventricular outflow tract. By presenting scanning electron micrographs of staged human embryos he demonstrated conclusively that closure of the embryonic interventricular foramen $\checkmark$ at the same time moulded the outflow tract from left ventricle to aorta. No active process of transfer was involved. The subsequent discussion highlighted the significance of the relative size of structures and their change with development and growth of the heart. The embryonic interventricular foramen never closed, but became moulded into the sub-aortic outflow tract. Professor W. Bersch followed with an account of the vectorial torsion hypothesis of Doerr and Goertler. He explained how the approach had been one of theoretical concept rather than anatomic reality. He agreed with Professor Pexieder that there was little evidence, or indeed need, to substantiate shrinkage of the outflow tract during incorporation of the aorta into the left ventricle. A series of slides presented by Professor $G$. Steding gave a different view of development of the outflow tract, not far removed from that of Dr Wenink. The crucial point which remained unanswered was the precise fashion in which the right atrium became connected to the right ventricle and consonant with this, the developing relationship between the tricuspid valve and the ventricular septum. This discussion was immediately followed by the demonstration by Professor F. Orts Llorca of a human embryo with complete transposition. It was pointed out that the problem with disagreements concerning its morphogenesis is related to the absence of a good animal model.

\section{Arterial portion}

The final series of presentations was devoted to the arterial pole of the heart. Dr H. M. Laane illustrated the confusion which arose through imprecise use of different descriptive terms. He then showed the results of his own studies on septation of the arterial trunks and the ventricular outflow tracts. The role of the truncus and the aortic sac in development of the great arteries was discussed. Professor Anderson then gave an account of how, for the formed heart, the distinction of ventriculoarterial connexions, arterial relationships and infundibular morphology had greatly simplified the description of so-called cono-truncal malformations. Professor Pexieder recognized the value of this approach for the formed heart, but felt that embryology was insufficiently advanced at this stage to identify the fate of any embryonic cardiac structure. Finally, Professor P. Krediet presented his work concerning the importance of haemodynamic factors. In his opinion, they were largely responsible for shaping many of the developmental processes previously discussed. The concepts he developed were based upon the interplay of two intertwining blood streams. Professor Los agreed that the crossing of the blood streams was essential for the development of the aortic-pulmonary septum.

\section{Summing up}

On this note the delegates moved to a final discussion so as to sum up the progress made during the meeting. It was agreed that during prenatal cardiac development there was a need to separate the stages of organogenesis and fetal growth. The division point was proposed as completion of ventricular septation.

The second summation related to the dangers of extrapolating from studies of formed and malformed hearts to establish concepts of development. It was argued there was equal danger in extrapolating from normal embryogenesis to explain fetal malformations. With these caveats in mind, both facets could be approached with an open mind. When speculations were made, they should be clearly identified as such.

The third point was to identify areas for intensive future studies. It was agreed that while there was now consensus concerning the connexion of the aorta to the left ventricle, the precise mechanics of arterial pole septation remained to be fully elucidated. Above all, the area which required concentrated study was the development of the right atrioventricular orifice and the origin of the inlet septum. It was resolved that these areas would be the topics for further presentation at the meeting of the working group scheduled at Spa, Belguim, in September 1983.

Finally, it was unanimously agreed that there was a need for a unified nomenclature to describe the developing heart. The two approaches considered were either to develop a new language completely, or else to take the existing terms, eradicate those which were considered unsuitable and to define precisely the suitable ones. While it was accepted that it would be difficult to create a totally new language, it was also agreed that most of the terms extant were more or less unsatisfactory. It was accepted that further discussions at this stage of 
the meeting were unlikely to prove constructive. Professor Pexieder therefore agreed to construct a draft nomenclature would be circulated to all members. Further discussion could then take place by correspondence and during the Spa meeting.

A symposium on clinically relevant cardiac embryology and teratology will be held during the European Congress of Cardiology in Dusseldorf during July 1984. The working group which will present this symposium, at present has about 30 members from most European countries. Any other

investigator interested in joining this group should contact either Professor Becker or Professor Pexieder.

A. E. BECKER Academisch Ziekenhuis bij de Universiteit van Amsterdam, Pathologie H2-135, Meibergdreef 9.

NL-1105 AZ Amsterdam. The Netherlands
T. Pexieder

Institut d'Histologie et d'Embryologie, rue du Bugnon 9. 1011 Lausanne-Chuv, Switzerland 